\title{
Cardiovascular Risk Factors in HIV-Infected Adults in North- Central Nigeria: Prevalence, Associated Factors and Assessment of Risk Using the Framingham Risk Score - Preliminary Results from a Survey
}

\author{
Amusa GA, ${ }^{I^{*}}$ Osaigbovo G, Imoh L, ${ }^{2}$ Awokola B. ${ }^{3}$ \\ ${ }^{\prime}$ Department of Medicine, University of Jos and Jos University Teaching Hospital, PMB 2076, Jos, Plateau State; Nigeria. \\ ${ }^{2}$ Department of Chemical Pathology, University of Jos and Jos University Teaching Hospital, PMB 2076, Jos, Plateau State; Nigeria. \\ ${ }^{3}$ Clinical Services Department, Medical Research Council, UK (The Gambia Unit), Greater Banjul, Gambia. \\ *Correspondence: Dr. Ganiyu Adeniyi Amusa \\ Email:drganiamusa@gmail.com, adeniyia@unijos.edu.ng \\ Article information \\ Date Submitted: $\quad 14 / 1 / 2021$ \\ Date Accepted: $\quad$ 23/3/2021 \\ Date Published: $\quad$ 18/4/2021
}

\begin{abstract}
HIV/AIDS is an increasingly important cause of cardiovascular (CVD) morbidity world-wide. We sought to evaluate the prevalence of CVD risk factors in HIV positive (HIV+) adults and assessment of these risks using the Framingham risk score (FRS). A cross-sectional study of adult clients of the HIV clinic at Jos University Teaching Hospital. One hundred and fifty HIV+ selected randomly with 50 (age and sex matched) HIV negative (HIV-) participants were enrolled. Relevant history, physical examination and biochemical investigations and 12-lead electrocardiography were performed. Data was analyzed using Epi-info 7.2 statistical software and $\mathrm{P}$ value $<0.05$ was considered significant. The prevalent major CVD risk factors were dyslipidaemia (30.0\% versus $6.0 \%)$, hypertension $(34.0 \%$ versus $10.0 \%)$ and diabetes mellitus $(10.0 \%$ versus $2.0 \%)$ among the HIV+ and HIV- participants respectively. The FRS of the HIV+, 3 (IQR 3-28) were statistically significantly higher than that of the HIV-participants, 2 (IQR 1-13); $\mathrm{P}=0.001$. Furthermore, $32 \%$ of the HIV+ had moderate-high FRS compared to $2 \%$ of HIV- participants. CD4 count $\leq 200$ cells $/ \mathrm{ml}$, use of anti-retroviral (ART), ART use $\geq 2$ years and use of protease inhibitors (PI) emerged as predictors of moderate-high FRS among the HIV+ participants. In conclusion, a high prevalence of CVD risk factors exists among HIV+ population in our local environment. These risk factors can be identified early by baseline/periodic cardiovascular work-up which should include use of CVD risk tools. Early diagnosis and treatment will significantly reduce morbidity and mortality in these patients.
\end{abstract}

Keywords: Anti-retroviral therapy, Cardiovascular disease riskfactors, Framingham risk score, HIV-infected Adults, Relative risk.

How to cite this article

Amusa GA, Osaigbovo G, Imoh L, Awokola B. Cardiovascular Risk Factors in HIV-Infected Adults in North-Central Nigeria: Prevalence, Associated Factors and Assessment of Risk Using the Framingham Risk Score - Preliminary Results from a Survey. J Biomed Res Clin Pract. 2021;4(1):71-83. doi.org/10.46912/jbrcp.208

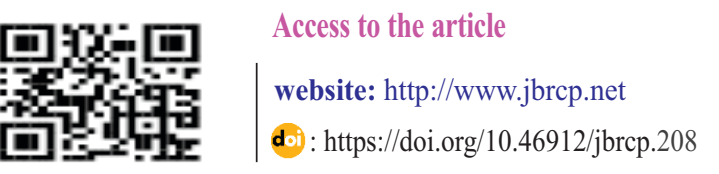




\section{INTRODUCTION}

$\mathrm{T}$ he acquired immune deficiency syndrome (AIDS) has been described as a global pandemic by the United nations (UN) and World Health Organization (WHO) ${ }^{1,2}$ The burden is disproportionately high in subSaharan Africa where it causes significant morbidity and mortality mostly in the young and productive age groups. ${ }^{1,2}$ Over 20 million deaths globally have been attributed to HIV infection, with about $75 \%$ of these occurring in sub-Saharan Africa alone. ${ }^{1,2}$

Nigeria has the second largest population of HIV infected persons in the world..$^{1-3}$ According to the 2018 Nigeria HIV /AIDS Indicator and Impact Survey (NAIIS), the current national prevalence is $3.1 \%$. With a population of more than 140 million people, this represents over $10 \%$ of the global pandemic in terms of absolute numbers.$^{1-3}$

The introduction of anti-retroviral therapy (ART) in 1996 has led to a gradual decline in morbidity, mortality rate and a change in causes of death in persons living with HIV/AIDS (PLWHA). ${ }^{4,5}$ Significant numbers of PLWHA are estimated to be over 50 years of age., ${ }^{4,5}$ This has brought to pre-eminence other causes of morbidity and mortality particularly cardiovascular diseases among PLWHA. ${ }^{1-5}$ HIV/AIDS is known to have a significant negative impact on the cardiovascular system in protean ways. ${ }^{6-9}$ The possible mechanistic pathways are the direct cardiotoxic effects of the virus, metabolic changes induced by the virus and ART, and certain predisposing lifestyles like smoking, alcohol abuse and drug abuse commoner among PLWHA. ${ }^{6-9}$ In PLWHA, concerns have been expressed about the emergence of a cardiovascular disease epidemic within the AIDS pandemic. ${ }^{1-5,10} \mathrm{~A}$ preponderance of studies report that CVD increasingly account for significant proportion of morbidity and mortality (30\% cause of mortality and more than 50\% increase in all-cause mortality) among PLWHA. ${ }^{11-16}$ Others have reported that certain classes of ART i.e. nucleoside reverse transcriptase inhibitors (NRTIs) and protease inhibitors (PIs) are associated with inducing metabolic syndrome which is a cluster of cardiovascular risk factors. ${ }^{17-23}$ Furthermore, some have advocated for HIV infection to be classified as a major CVD risk factor. ${ }^{10}$ Collectively these studies indicate that theshort and long term risks of ART may differ but there is no question that the use of ART to ensure adequate viral suppression is paramount to the successful clinical management of HIV infected patients despite its long term attendant risk. There is a growing call for baseline/periodic assessment of CVD risk factors in PLWHA. The FRS has been found useful in assessing CVD risk in PLHWA and has been validated for use among different races. ${ }^{24-27}$ This study aims to add to the available evidence in literature on the burden of CVD risk factors and assessment of CVD risk using the FRS in Nigeria where similar studies are very few.

\section{MATERIALSAND METHODS}

This was a hospital based cross sectional analytical study conducted in the HIV clinic of JUTH in NorthCentral Nigeria. The study aimed to determine the prevalence of specific CVD risk factors and assessment of these risks with the FRS. One hundred and fifty adult HIV+ participants (90 on ART, 60 not ART) with fifty age and sex-matched HIV- as controls were enrolled into the study in a simple random manner over a period of four months. Those with acute illnesses and pregnancy were excluded. The HIV- controls were enrolled from clients of the HIV clinic who underwent HIV counselling and testing and were tested negative for HIV. The ethical approval for the study was obtained from the Human Research and Ethics Committee of JUTH. The nature of the study was explained to each participant in the language they best understand. Consenting participants were required to sign the consent forms, or append their thumb print where appropriate. Participants were at liberty to withdraw from the study at any stage without consequence and information obtained was treated as confidential. 
Each participant was interviewed to obtain relevant demographic and clinical history. They were also grouped into social class using a Nigerian method by Olusanya et al. ${ }^{28}$ Physical activity was graded according to the WHO guidelines. ${ }^{29}$ Anthropometric and cardiovascular examinations were performed and documented. Weight was recorded in kilograms to the nearest $0.1 \mathrm{~kg}$ using a flat scale on a firm horizontal surface with subjects wearing only light clothes and without shoes and head gears. ${ }^{30}$ Height was recorded in metres with a stadiometer positioned on a flat surface and recorded to the nearest 0.01 metre. Height measurements were taken without shoes and head gears. ${ }^{30}$ Body mass index (BMI) was calculated as the weight divided by the square of the height and recorded in $\mathrm{Kg} / \mathrm{m}^{2} .^{30}$ The body surface area (BSA) was calculated using the Mosteller Formula $\left(\right.$ BSA $\left(\mathrm{m}^{2}\right)=[$ Height $(\mathrm{cm}) \times$ Weight $\left.(\mathrm{Kg}) / 3600]^{1 / 2}\right){ }^{31}$ Waist circumference (WC) was measured in centimetres using a non-stretch metric tape on bare skin at the horizontal level at a point mid-way between the lowest rib and the iliac crest at the end of a gentle expiration. ${ }^{30}$ Hip circumference (HC) was measured in centimetres using a non-stretch metric tape on bare skin at the horizontal level of maximum circumference around the buttocks and the pubic symphysis. ${ }^{30}$ Blood pressure was measured using a standard mercury sphygmomanometer with appropriate cuff size in both in both arms in sitting position after a 510 minutes rest. Values corresponding to the first and fifth Korotkoff sounds were considered as the systolic and diastolic blood pressures respectively. Two additional recordings were made using the limb with the higher value; the average was taken to give a representative value.

On completion of physical examination, $10 \mathrm{mls}$ of fasting venous blood was drawn from each patient and put into appropriate specimen bottles for the following investigations; serum lipid profile, plasma glucose, serum creatinine and uric acid. Low density lipoprotein (LDL) was calculated using the Friedewald formula $(\mathrm{LDL}=\mathrm{TC}$ HDL - TG/2.2; all in $\mathrm{mmol} / \mathrm{L}),{ }^{32}$ and estimated glomerular filtration rate was calculated using the MDRD calcolator. ${ }^{33}$ Each participant thereafter had twelve lead electrocardiography done using General Electric Medical Systems Information Technologies MAC 1200 ST v.1.2 electrocardiograph machine. Standard values were used for the various components and the various patterns obtained were interpreted according to standard definitions. Left ventricular hypertrophy was documented when present. The FRS for each participant was calculated using the online FRS calculator. ${ }^{34,35}$ Further relevant clinical information (duration of HIV, history and duration of ART, clinical history of CVD risk factors, baseline and recent CD4 count and viral load) were obtained from the records of each participant.

\section{Definition of Operational Terms}

1. Hypertension: Persistent elevation of blood pressure $\geq 140 / 90 \mathrm{mmHg}$ according to JNC V11 classification or current use of antihypertensive medication. ${ }^{36}$

2. Impaired fasting blood sugar: fasting glucose $\geq 5.6$ $\mathrm{mmol} / \mathrm{l}^{37}$

3. Dyslipidaemia: Total cholesterol $\geq 6.2 \mathrm{mmol} / \mathrm{l}$ and/or $\mathrm{HDL} \leq 1.1 \mathrm{mmol} / 1(40 \mathrm{mg} / \mathrm{dl})$ in male and $1.3 \mathrm{mmol} / 1$ $(50 \mathrm{mg} / \mathrm{dl})$ in female and/or artherogenic index $\geq 4.5{ }^{38}$

4. Waist circumference ${ }^{30}$ (abnormal): Females $\geq 80 \mathrm{~cm}$, Male $\geq 94 \mathrm{~cm}$

5. Waist hip ratio ${ }^{30}$ (abnormal): Females $\geq 0.85$, Male $\geq$ 0.9

6. Body mass index ${ }^{30}\left(\mathrm{~kg} / \mathrm{m}^{2}\right)$ : Underweight $\leq 18.5$, Normal weight 18.5-24, Overweight $25.0-29.9$, Obesity $>30.0$.

7. Metabolic syndrome ${ }^{39}$ : According to IDF criteria; increased waist circumference (population specific) and any two of the following:

Triglyceride $\geq 150 \mathrm{mg} / \mathrm{dl}$ or HDL-C $\leq 40 \mathrm{mg} / \mathrm{dl}$ in male and $\leq 50 \mathrm{mg} / \mathrm{dl}$ in female or on treatment for lipid abnormalities.

Blood pressure $\geq 130 / 85 \mathrm{mmHg}$ or on antihypertensives.

Fasting plasma glucose $\geq 100 \mathrm{mg} / \mathrm{dl}$ or previously 
diagnosed with diabetes mellitus.

8. Framingham risk scores triages patients into three risk categories: high risk (10-year risk $>$ $20 \%$ ), moderate risk ( 10 -year risk $10 \%$ to $20 \%$ ), or low risk $(10$-year risk $<10 \%){ }^{24,40}$ Individuals with clinical form of cardiovascular disease or with diabetes belong in the high risk category. ${ }^{24,40}$ Moderate risk also includes patients with 2 or more major risk factors and 10-year risk $<10 \%$. Low risk patients are those with 1 major risk factor or none and 10 -year risk $<10 \%$. ${ }^{24,40}$

\section{Statistical analysis}

Data was analyzed using the EPI- Info version 7.2.2.6 (CDC Atlanta, Georgia USA) statistical software. Quantitative variables were summarized using mean and standard deviation (SD). Categorical variables were expressed using frequencies and percentages with confidence intervals stated. The student $\mathrm{t}$-test or non-parametric Mann-Whitney/Kruskal-Wallis tests was used to compare means of 2 groups. The Chi Square $\left(\mathrm{X}^{2}\right)$ test was used to test the significance of association between categorical variables. Where the expected frequency of a cell was $<5$, Fisher's exact test was used. Multiple logistic regression analysis was performed to determine which HIV parameters (CD4 $\geq 200$ cells $/ \mathrm{ml}$, detectable viral load, ART use, ART use $\geq 2$ years and protease inhibitors use) are predictors of moderate-high FRS using variables that had a $p$-value of $<0.05$ on univariate analysis. In all cases, $\mathrm{p}$ - value of $<0.05$ was considered statistically significant.

\section{RESULTS}

One hundred and fifty HIV+ participants (90 ART experienced and 60 ART naive) and 50 age and sex matched HIV-controls were enrolled for this study. Everyone completed the study.
Table 1: Baseline socio-demographic characteristics of study participants

\begin{tabular}{llll}
\hline Variable & $\begin{array}{l}\text { HIV+ } \\
\text { N=150(\%) }\end{array}$ & $\begin{array}{l}\text { HIV- } \\
\text { N=50(\%) }\end{array}$ & P-value \\
\hline Gender frequency: & & & \\
Female & $94(62.7)$ & $30(60.0)$ & 0.740 \\
Male & $56(37.3)$ & $20(40.0)$ & \\
Age (Mean \pm SD): & $40.61 \pm 7.5$ & $40.2 \pm 7.9$ & 0.770 \\
Marital status: & & & \\
Single & $86(57.3)$ & $15(30.0)$ & $0.001^{\mathrm{x}}$ \\
Married & $64(42.7)$ & $35(70.0)$ & \\
Social class: & & & \\
1 & $7(4.7)$ & $3(6.0)$ & $0.347^{+}$ \\
2 & $10(6.7)$ & $4(8.0)$ & \\
3 & $20(13.3)$ & $9(18.0)$ & \\
4 & $44(29.3)$ & $19(38.0)$ & \\
5 & $69(46.0)$ & $15(30.0)$ & \\
Residence: & & & \\
Urban & $92(61.3)$ & $36(72.0)$ & 0.170 \\
Rural & $58(38.7)$ & $14(28.0)$ & \\
\hline
\end{tabular}

${ }^{+}$Fishers exact $P, \quad{ }^{\mathrm{x}}$ Significant

Table 2: Clinical characteristics of study participants

\begin{tabular}{|c|c|c|c|}
\hline Variable & HIV+ & HIV- & P-value \\
\hline \multicolumn{4}{|l|}{ Anthropometry } \\
\hline $\mathrm{BMI}^{\mathrm{a}}\left(\mathrm{kg} / \mathrm{m}^{2}\right)$ & $22.47 \pm 3.42$ & $24.43 \pm 2.18$ & 0.001 \\
\hline $\mathrm{WC}^{\mathrm{b}}(\mathrm{cm})$ & $82.83 \pm 5.98$ & $83.96 \pm 4.05$ & 0.206 \\
\hline $\mathrm{WHR}^{\mathrm{c}}$ & $0.81 \pm 0.05$ & $0.81 \pm 0.04$ & 0.795 \\
\hline \multicolumn{4}{|l|}{ Cardiovascular } \\
\hline Pulse rate $(\mathrm{b} / \mathrm{m})$ & $88.15 \pm 16.54$ & $79.36 \pm 8.16$ & 0.795 \\
\hline Systolic BP (mmHg) & $124.68 \pm 17.92$ & $124.60 \pm 12.09$ & 0.976 \\
\hline Diastolic BP $(\mathrm{mmHg})$ & $86.14 \pm 11.7$ & $81.36 \pm 8.58$ & 0.008 \\
\hline MABP (mmHg) & $99.05 \pm 16.64$ & $96.48 \pm 10.70$ & 0.290 \\
\hline \multicolumn{4}{|l|}{ Biochemical } \\
\hline FBS (mmol/l) & $5.04 \pm 1.03$ & $4.89 \pm 0.61$ & 0.336 \\
\hline $\mathrm{TC}(\mathrm{mmol} / / \mathrm{l})$ & $4.14 \pm 0.99$ & $4.81 \pm 0.72$ & 0.001 \\
\hline $\mathrm{HDL}(\mathrm{mmol} / \mathrm{l})$ & 1.00 (IQR $0.8-1.3)$ & 1.85 (IQR 1.6 - 2.6) & 0.001 \\
\hline LDL (mmol/l) & 2.35 (IQR 1.8 - 2.7) & 2.35 (IQR 2.2 - 3.3) & 0.349 \\
\hline $\mathrm{TG}(\mathrm{mmol} / \mathrm{l})$ & $1.40(\mathrm{IQR} 1.0$ - 1.9$)$ & 1.15 (IQR 0.9 - 1.6) & 0.045 \\
\hline $\mathrm{AI}(\mathrm{mmol} / \mathrm{l})$ & 3.80 (IQR 3.0 - 4.9) & $2.60($ IQR $2.4-6.5)$ & 0.001 \\
\hline $\mathrm{Cr}(\mathrm{umol} / \mathrm{l})$ & 107 (IQR 90 - 429) & 97 (IQR 88 - 120) & 0.015 \\
\hline $\mathrm{eGFR}\left(\mathrm{ml} / \mathrm{min} / \mathrm{m}^{2}\right)$ & 74 (IQR $13-96)$ & 97 (IQR 71 - 106) & 0.010 \\
\hline
\end{tabular}

${ }^{x}$ Significant, ${ }^{a}$ body mass index, ${ }^{b}$ waist circumference, ${ }^{c}$ waist hip ratio, HIV $+(H I V$ positive), HIV- (HIV-negative), BP-blood pressure, MABP-mean arterial blood pressure, FBS - fasting blood sugar, TC-total cholesterol, HDL-high density lipoprotein, $L D L$ - low density lipoprotein, AI- atherogenic index, $\mathrm{Cr}$-creatinine, eGFR-estimated glomerularfiltration rate. 
Table 1 shows the sociodemographic characteristics of the study participants. The HIV+ participants were 94 females and 56 males; there were 30 females and 20 males HIV-as controls (Table 1). The mean age of the HIV+ was $40.6 \pm 7.5$ years and $40.2 \pm 7.9$ years for HIV-. The commonest social class among the subjects was social class $5(46.0 \%)$ while that of the controls was social class 4 (38.1\%); the difference in social class was not statistically significant $(\mathrm{p}>0.05)$.

Table 2 shows the clinical characteristics of the study participants. The mean BMI was $22.47 \pm 3.42$ and $24.43 \pm$ 2.18 respectively in the HIV+ and HIV- participant, $\mathrm{P}=0.001$. The difference in waist circumference and waist-hip ratio between both groups were not statistically significant. The cardiovascular parameters of pulse rate, systolic blood pressure and mean arterial blood pressure

Table 3: Prevalence of cardiovascular disease risk factors and degree of clustering

\begin{tabular}{|c|c|c|c|}
\hline Variable & $\begin{array}{l}\text { HIV+ } \\
\mathrm{N}=150(\%)\end{array}$ & $\begin{array}{l}\text { HIV - } \\
\mathrm{N}=50(\%)\end{array}$ & P-value \\
\hline Hypertension 1 & $51(34.0)$ & $5(10.0)$ & $0.001^{\mathrm{x}}$ \\
\hline Diabetes Mellitus ${ }^{1}$ & $15(10.0)$ & $1(2.0)$ & $0.001^{\mathrm{x}}$ \\
\hline Dyslipidaemia $^{1}$ & $45(30.0)$ & $3(6.0)$ & $0.001^{\mathrm{X}}$ \\
\hline Metabolic syndrome $^{1}$ & $14(9.3)$ & $1(2.0)$ & $0.001^{x}$ \\
\hline Hyperuricaemia & $12(8.0)$ & $0(0)$ & $0.001^{\mathrm{x}}$ \\
\hline Left Ventricular hypertrophy & $25(16.7)$ & $2(4.0)$ & $0.003^{\mathrm{x}}$ \\
\hline Overweight/Obesity & $40(26.7)$ & $18(36.0)$ & 0.210 \\
\hline Increased Waist Circumference & $48(32.0)$ & $15(30.0)$ & 0.790 \\
\hline Increased Waist/Hip Ratio & $14(9.3)$ & $3(6.0)$ & 0.570 \\
\hline Significant Alcohol Intake ${ }^{1}$ & $47(31.3)$ & $6(12.0)$ & $0.001^{\mathrm{x}}$ \\
\hline Smoking ${ }^{1}$ & $32(21.3)$ & $2(4.0)$ & $00.01^{\mathrm{x}}$ \\
\hline Inadequate Physical Exercise & $145(96.7)$ & $43(86.0)$ & $0.001^{\mathrm{x}}$ \\
\hline Low Socio - economic Class & $113(75.3)$ & $34(68.0)$ & 0.190 \\
\hline \multicolumn{4}{|l|}{ Degree of Clustering } \\
\hline 0 Risk factors & $27(18.0 \%)$ & $19(38.0 \%)$ & $0.001^{\mathrm{x}}$ \\
\hline 1-2 Risk factors & $47(31.33)$ & $28(56.0 \%)$ & \\
\hline 3-4 Risk factors & $39(26 \%)$ & $3(6.0 \%)$ & \\
\hline$>4$ Risk factors & $37(24.67 \%)$ & $0(0.0 \%)$ & \\
\hline
\end{tabular}

Table 4: Framingham risk scores and relative risk in study participants

\begin{tabular}{llll}
\hline Variable & $\begin{array}{l}\text { HIV+ } \\
\text { N=150(\%) }\end{array}$ & $\begin{array}{l}\text { HIV- } \\
\text { N=50(\%) }\end{array}$ & P-value \\
\hline $\begin{array}{l}\text { Framingham Risk Score } \\
\text { FRS grades }\end{array}$ & IQR 3-28) & $2($ IQR 1-13) & $0.001^{\mathrm{X}}$ \\
$\begin{array}{l}\text { Low risk } \\
\text { Moderate risk }\end{array}$ & $99(66.0 \%)$ & $49(98.0 \%)$ & $0.001^{\mathrm{X}}$ \\
High risk & $40(26.7 \%)$ & $1(2.0 \%)$ & \\
Relative Risk & $11(7.3 \%)$ & $0(0.0 \%)$ & \\
\hline
\end{tabular}

${ }_{\text {Significant, }}{ }^{a}$ Ratio of index FRS divided by that ideal for age
Table 5: Multiple Logistic Regressions for Independent Predictors of Moderate- High Framingham Risk Score

\begin{tabular}{llll}
\hline Term & Odds Ratio & 95\% CI & P value \\
\hline CD4 $\leq 200$ cells $/ \mathrm{mm}^{3}$ & 2.8147 & $1.0159-7.7989$ & $0.0466^{\mathrm{X}}$ \\
Detectable Viral load $\geq 200 \mathrm{c} / \mathrm{ml}$ & 7.1022 & $0.7996-63.3221$ & 0.0790 \\
ART experienced & 0.0942 & $0.0094-0.9487$ & $0.0450^{\mathrm{X}}$ \\
ART duration $\geq 2$ years & 2.3729 & $1.3589-12.6606$ & $0.0256^{\mathrm{X}}$ \\
Protease inhibitors use & 10.5354 & $2.3816-46.6058$ & $0.0019^{\mathrm{X}}$ \\
\hline
\end{tabular}

${ }^{x}$ Significant, ART-antiretroviral therapy, CI-confidence interval 
did not show statistically significant difference across the groups, however there was a statistically significant difference in the mean diastolic blood pressure across the two groups, $\mathrm{P}=0.008$. There was statistically significant difference in the total cholesterol, HDL, triglycerides, atherogenic index, serum creatinine and estimated glomerular filtration rate across the two groups. The difference in the fasting blood sugar and LDL was not statistically significant across the groups.

Table 3 depicts the prevalence of specific CVD risk factors and their degree of clustering across the groups. The prevalence of specific CVD risk factors in the HIV+ are hypertension $34 \%$, diabetes $10 \%$, dyslipidaemia $30.0 \%$, metabolic syndrome $9.3 \%$ and smoking $21.3 \%$. Others are as shown in the table. There was statistically significant difference in the degree of clustering of the CVD risk factors across the 2 groups, $\mathrm{P}=0.001$.

Table 4 depicts the Framingham risk score and grades and relative risks of the participants. There was statistically significant difference in the FRS and relative risks across the 2 groups, $\mathrm{P}=0.001 .34 \%$ of the HIV+ have moderatehigh FRS compared to $2 \%$ of the HIV-.

Table 5 depicts the results of multiple logistic regression analysis to determine which HIV parameters (CD4 $\leq 200$ cells $/ \mathrm{ml}$, detectable viral load ( $\leq 200$ copies $/ \mathrm{ml}$ ), ART use. duration of ART use $\geq 2$ years and use of protease inhibitors) emerged as predictors of moderate-high FRS. CD 4 count $\leq 200$ cells $/ \mathrm{ml}$, use of ART, ART duration $\geq 2$ years and use of protease inhibitors emerged as predictors of moderate-high FRS in the HIV+ participants.

\section{DISCUSSION}

HIV/AIDS is a global pandemic with preponderance of burden in sub-Saharan Africa where a significant amount of morbidity and mortality occurs. ${ }^{1-3}$ Coupled with the burdens of other communicable and non-communicable diseases; HIV/AIDS predominantly affects the young and productive age-group in SSA with consequent socioeconomic devastation in societies where the prevalence is high. ${ }^{1-3}$ The virus affects every system in the human body often causing multiple morbidities in infected and affected individual. ${ }^{1-3,6-16}$ The cardiovascular system in particular is affected by HIV/AIDS in protean ways with consequent increase in morbidity and mortality. ${ }^{6-8}$ This study set out to evaluate the prevalence of specific cardiovascular disease risk factors, assessment of these risks using the Framingham risk score and the predictors of moderate-high Framingham risk scores in persons living with HIV/AIDS seen at the HIV clinic of Jos University Teaching Hospital.

A total of $150 \mathrm{HIV}+$ and $50 \mathrm{HIV}$ - participants who met the study criteria were enrolled. There were more females than males and majority were in the fourth decade of life. This was expected and is comparable to what obtains generally in Nigeria and in most parts of sub-Saharan Africa where majority of PLWHA are young and in the productive age group. ${ }^{1-3}$ About $57 \%$ of the subjects in this study were single ( $20 \%$ due to loss of spouse), the disease tends to decimate families with loss of a either or both spouses common in affected families. ${ }^{1-3}$ In this study most of the subjects were either unemployed or self-employed, reside in urban areas and belonged to the low socioeconomic class. This was expected and is in agreement with studies which identify HIV infection in Africa as a disease that in most cases is associated with low socioeconomic class and societal economic retardation. ${ }^{1-3,41}$

The HIV+ participants and HIV-participants in this study were age and sex matched, they were also of comparable socio-demographic status. Therefore, the difference in the findings between them may to a large extent be due to the difference in their HIV status. The human immuno-deficiency virus causes pathologic cardiovascular and metabolic changes that may be detected even in the early stages of the disease. ${ }^{6-9}$ This in addition to adverse lifestyle predisposes PLHWA to cardiovascular disease. ${ }^{41-44}$ 
Prevalence of specific cardiovascular disease risk factors in PLWHA

Low socio-economic class: The difference in social class of HIV+ and HIV-participants in this study did not attain statistical significance. This shows that the differences in the prevalence of cardiovascular risk factors and Framingham risk scores found may have been due to the virus and its associated factors. Studies have identified extremes of social class as a risk factor for cardiovascular diseases in the general population. ${ }^{24,28,35,37,40,41}$ Furthermore in PLWHA, low socio-economic class has been identified as a significant predictor of increased cardiovascular risk score and disease. In a large multicenter study involving 931 men and 1455 women with HIV infection in the United states. Robert Kaplan et al concluded that having a low socio-economic class (income less than 10,000 dollars/year) was associated with increased prevalence of moderate-high coronary heart disease risk scores in PLWHA. ${ }^{41}$ Infact, among the factors considered; belonging to a lower socio-economic class was the strongest risk factor identified to having a moderate-high CHD risk score (OR 2.32, 95\%CI 1.51-3.36). ${ }^{41}$ Similar findings have been obtained by several other studies on risk factors for cardiovascular abnormalities in HIV infected persons. ${ }^{17-19,41,46}$

Predisposing lifestyles: A significant number of the $\mathrm{HIV}+$ participants $(21.3 \%)$ smoke, take alcohol in significant quantities $(31.3 \%)$ and do not engage in significant physical exercises $(97.0 \%)$. Among the controls, only $4 \%$ smoke and $12 \%$ take alcohol in significant quantities; this is comparable to results obtained in other studies which report that risky lifestyle is commoner in HIV infected persons. ${ }^{41-52}$ These habits significantly promote cardiovascular diseases and are commoner in those who experience stigma..$^{41-44}$ Recent evidences suggest that smoking and alcoholism reduces the efficacy of anti-retroviral therapy, reduces immunity and promotes vascular disease, atherosclerosis, hypertension and other co-morbidities. ${ }^{41-43}$ They have also been shown to increase all-cause mortality in PLWHA. ${ }^{1}$ ${ }^{6,10-14}$ Inadequate physical activity was more prevalent in the HIV+ participants; this may be due to the chronicity and debilitating nature of the disease. HIV infection predisposes its victim to long periods of physical inactivity with its attendant consequences. Lack of exercises has been shown to have an adverse impact on blood glucose levels, blood pressure and lipid profiles; it also raises the risk of a cardiovascular event by twofold. . $^{8,182,43,53}$

Overweight/Obesity: Excess body mass index (BMI $\geq 25$ ) was found in $26.7 \%$ of HIV + participants and $32 \%$ had increased waist circumference. The HIVparticipants however had higher mean values of weight and BMI; this may be due to the fact that HIV is a chronic infection which results in progressive weight loss especially in those not yet on ART. ${ }^{6-11,15,16,42,43}$ Among the HIV+ participants, those on ART had statistically significant mean values of weight, body mass index, waist circumference and waist-hip ratio compared to those not on ART. A recent study in fact found that being overweight or obese is now more prevalent than wasting in PLWHA. ${ }^{42,43}$ Increased mortality rates have been identified as an exponential function of increasing body weight. ${ }^{39,42,43,54}$ The risk of coronary heart disease doubles with BMI greater than 25 and increases nearly fourfold when it is above $29 .^{39,54}$ The risk of developing type 2 diabetes also increases with increasing weight such that individuals with a BMI above 35 have about 40-fold higher risk of developing diabetes when compared to non-obese individuals. $37,39,42,43,54$

In people with normal BMI, increased waist circumference has a positive correlation with abdominal fat content. Fat located in the abdominal region is associated with a greater health risk than peripheral fat..$^{37,39,42,43,54}$ This study also showed that increased wait-hip ratio is commoner in the HIVinfected population compared to controls. Many studies on cardiovascular risk factors in HIV persons have showed evidence of increased alteration of body shape 
and size in HIV infected persons with its attendant consequences. ${ }^{37,39,42,43,54}$

Diabetes mellitus: A significant number of HIV+ participants $(10.0 \%)$ had impaired glucose tolerance compared to $2 \%$ of the controls. This occurred mostly in those on ART and showed a strong statistically significant difference when compared to those not on ART. Some studies had reported the prevalence of type 2 diabetes mellitus among patients with HIV to range from $6 \%$ to $18 \%{ }^{1,2,15-23,54-56}$ Reasons that have been reported to predispose PLWHA to diabetes are exposure to ART particularly protease inhibitors, male gender, aging, changes in body shape and size, as well as ethnicity and hepatitis $\mathrm{C}$ co-infection. ${ }^{4,5,15-23,42,43,45-52}$

Dyslipidaemia: Dyslipidaemia is a significant predictor of endothelial dysfunction and atherosclerosis in the general population. ${ }^{35,39,40}$ It was found in more than $30 \%$ of the HIV+ participants and only $6 \%$ of the HIV-. Literature search revealed a prevalence that ranges from $28-80 \%$ in patients receiving ART. ${ }^{15-23,45-47,49}$ In general, use of protease inhibitors have been associated with more adverse lipid changes than use of other classes of ART. ${ }^{15-19,21-23}$ In addition untreated HIV infection is associated with decreased total and HDL cholesterol with increased triglcerides. ${ }^{46-52,54-57}$ This is in addition to adverse dietary habits which contribute to dyslipideamia and are commoner in PLWHA. ${ }^{15,16,42-44}$ Dietary modification may therefore be needed as part of management modalities. ${ }^{15,16}$

Hypertension: Hypertension was found in 34\% of the HIV+ participants, $40 \%$ of those on ART and $25 \%$ of those not on ART were found to have hypertension. Only $10 \%$ of the HIV- participants had hypertension. Hypertension is a common and important major risk factor for cardiovascular disease. ${ }^{24,35,36}$ In PLWHA, literature search reveals a prevalence that ranges from 8 $74 \%{ }^{9,14-16,18,20,41,48-52,54-58}$ It is known that the impact of hypertension on morbidity and overall mortality rate is much higher among PLWHA than in the general population, hypertension increases the all-cause mortality in PLWHA by more than $50 \%$. ${ }^{45,47,50,51,54-58}$ Furthermore, studies have shown that hypertension in PLWHA is related to the nadir CD4 count and by extension the severity of the disease. ${ }^{55,56,57}$ Hypertension has been described as a harbinger of other CVD risk factors, this may be due to a central pathophysiologic pathway for CVD risk factors; it is easily detectable and is thus central in management of CVD risks. ${ }^{9,15,16,35,39,50-}$ ${ }^{52,54-58}$ Experts in resource poor setting like ours must take advantage of this to manage cardiovascular risks in PLWHA and the general population.

Metabolic syndrome: About $25 \%$ of the HIV+ participants had at least 4 identified cardiovascular disease risks, those on ART had higher clustering of risks compared to those not on ART. Metabolic syndrome using the IDF criteria was found in almost $9.3 \%$ of the HIV+ participants, majority of who were on ART. Although the exact prevalence is not known in PLWHA, some have estimated it as high as $32 \%$. $^{11-13,15-23}$ Metabolic syndrome refers to a cluster of certain specific CVD risks which occurs in different combinations and is not due to chance alone. ${ }^{35,39}$ The individual risks sum up and increases risk exponentially resulting in a chronic pro-thrombotic and proinflammatory state with attendant morbidity. ${ }^{35,39}$

\section{Cardiovascular risk assessment using the Framingham risk scores}

In this study, the HIV+ participants had statistically significantly higher values of Framingham risk scores (FRS) compared to the HIV-controls. Likewise, those on ART also had statistically significantly higher values of FRS compared to those not on therapy. Among those on ART, those on protease inhibitor-based therapy had statistically significantly higher values of FRS compared to those not on protease inhibitor-based therapy. These findings are in keeping with reports from several other studies..$^{17-19.25,26,41,46,49}$ A major and landmark study, 'Data on Adverse Effects of Antiretroviral 
therapy' survey reported similar findings of increased cardiovascular risk in persons on ART especially the PI based one. ${ }^{18,19}$ Reasons suggested for this is that HIV and ART may have elaborative influence on traditional and non-traditional CVD risk factors by multifactorial pathways. ${ }^{6-10,15,1,21}$ However, it is generally agreed that knowing the CVD risk and acting on it is imperative to long term survival in HIV-infected persons. There is a growing call for HIV infection to be classified as a major CVD risk factor on account of the significant effect of the virus and ART on the cardiovascular system. ${ }^{10}$

\section{Predictors of moderate-high Framingham risk scores in PLWHA}

This study set out to look at the specific HIV-related parameters i.e., ART use, ART duration, use of proteaseinhibitor based regimen, CD4 count $\leq 200 \mathrm{cells} / \mathrm{ml}$, and detectable viral load ( $\geq 200$ copies $/ \mathrm{ml}$ ) rather than the traditional CVD risk factors as independent predictors of moderate-high FRS among PLWHA. Moderate-high FRS connotes significant increase in the likelihood of occurrence of a cardiovascular event or disease hence infers adverse prognosis. . $^{2,35}$

The presence of moderate-high Framingham risk score was significantly associated to all the HIV-related parameters examined on univariate analysis. However, on multiple logistic regression analysis; $\mathrm{CD} 4$ count $\leq 200$ cells $/ \mathrm{ml}$, ART duration $\geq 2$ years and use of protease inhibitor-based regimen emerged as independent predictors of moderate-high FRS in the HIV+ group. Paradoxically, use of ART generally appears to be protective to getting moderate-high FRS (OR 0.0942, $95 \%$ CI $0.0094-0.9487, \mathrm{P}=0.0450$ ), perhaps due to the overall initial improvement in the state of health when ART is started i.e., marked reduction in chronic inflammatory markers, reduction in viral load etc. The initial effects of ART become attenuated over time with emergence and accentuation of chronic complications ART use (dyslipidaemia, lipodystrophy, metabolic/mitochondrial re-programming, cardiovascular toxicity etc.). The results in this study appears to suggest ART being initially protective against elaboration of CVD risks and thence moderatehigh FRS, the initial protection is lost after 2 years when the complications of ART use sets in (OR 2.3729, 95\%CI 1.3589-12.6606, $\mathrm{P}=0.0256$ ). Reports from studies appears to be ambivalent with regards to the role of ART on CVD risks, ${ }^{11-23,41,45-58}$ some studies however align with the finding in this study $;^{17-23,54-58}$ the reasoning behind the results in this study also appears scientifically rational and plausible. ${ }^{4-10}$ Detectable viral load $(\geq 200 \mathrm{c} / \mathrm{ml})$ didn't emerge as an independent predictor perhaps due to the rapid flux rate of viral load, other studies also report similar findings. CD4 count $\leq 200 \mathrm{cells} / \mathrm{ml}$ was found to be a predictor of moderatehigh FRS, low CD4 count signifies chronic inflammatory state (with consequent re-setting of immunologic memory) and severity of HIV infection and unlike viral load is not prone to rapid flux rate. ${ }^{6-10}$ Baseline (nadir or trough) and recent CD4 count have been reported in some studies to be related to the development of hypertension and other CVD risk factors in PLWHA. ${ }^{17-23,5458}$ Similarly, use of protease inhibitor-based regimen was found to predict moderatehigh FRS in this study perhaps due to the consequences of pathologic mitochondrial and metabolic changes induced by protease inhibitors. The finding is in agreement with reports from other studies. ${ }^{17-19,21-23,41}$

\section{CONCLUSION}

Cardiovascular disease risk factors are prevalent in PLWHA in our local environment. Early identification and assessment of these risk using a CVD risk assessment tool such as the Framingham risk score is advocated with prompt intervention to decrease morbidity, improve quality of life and reduce mortality these patients.

\section{Recommendations}

It is recommended that baseline and routine screening for CVD risk factors and assessment of these risks using 
the Framingham risk score be integrated in the algorithm for treatment of HIV-infected persons in Nigeria.

\section{Limitations}

This study was conducted in a single centre (although the centre serves North-central Nigeria and beyond) with limited number of participants, a large multi-centre study will be more representative.

\section{Acknowledgements}

This is to acknowledge the contributions of Professor BN Okeahialam, Professor SS Danbauchi, Professor DA Oke, Dr Onuh James, Dr Muoneme Sandra and Dr Uche Uguru to the completion of this study. The author also received research grant and manuscript writing training from STAMINA funded by the NIH under Award Number D43 TW010130. Research methodology and manuscript writing training was also received from PATSMECOR and Global MECOR programs of the American Thoracic Society.

\section{Conflict of interests}

None

\section{REFERENCES}

1. UNAIDS data 2020 .

https://www.unaids.org/sites/default/files/media asset /2020 aids-da ta-book_en.pdf. (accessed 01/02/2021).

2. Global AIDS Update. https://www.unaids.org/sites/default/files/media_asset 12020 glob al-aids-report executivesummary en.pdf. (accessed 22/01/2021).

3. Nigeria National HIV/AIDS Indicator and Impact Survey (NAIS). https://www.unaids.org/en/r esources/presscentre/pressreleaseandstatementarchive /2019/march/20190314_nigeria. (accessed 22/01/2021).

4. Palella FJ, Delaney KM, Moorman AC, Loveless MO, Furher J, Satten GA et al. Declining morbidity and mortality among patient with advanced HIV infection,
N Engl J Med 1998; 338: 853-860.

5. Effros RB, Fletcher CV, Gebo K, Halter JB, Hazzard WR, Home FM. Aging and Infectious diseases: workshop on HIV infection and aging: what is known and future research directions. Clin Infect Dis.2008; 47:542-553.

6. Armah KS, Benjamin LA, Bloomfield GS, Feinstein MJ, Hsue P, Freiberg MS, et al. HIV and cardiovascular disease. Lancet HIV 2020; 7 : e279-93.

7. Boccaraa F, Cohen A. HIV and Heart Disease: What Cardiologists Should Know. Rev Esp Cardiol. 2016;69(12):1126-1130.

8. Hsue PY, Deeks SG, Hunt PW. Immunologic basis of cardiovascular disease in HIV-infected adults. J Infect Dis 2012;205(Suppl 3):S375-82.

9. Masenga SK, Hamooya BM. Nzala S, Kwenda G, Heimburger DC, Kirabo A, et al. Patho-immune Mechanisms of Hypertension in HIV: A Systematic and Thematic Review. Current Hypertension Reports 2019; 21: 56 https://doi.org/10.1007/s11906-019-0956-5.

10. Hsue PY, Waters DD. Time to Recognize HIV Infection as a Major Cardiovascular Risk Factor. Circulation. 2018;138:00-00. DOI: 10.1161/CIRCULATIONAHA.118.036211.

11. Shah A, Stelzle D, Lee KK, Beck EJ, McAllister DA, Mills NL, et al. Global burden of atherosclerotic cardiovascular disease in people living with the human immunodeficiency virus: a systematic review and meta-analysis. Circulation 2018;138(11):1100-1112.doi:10.116 1/CIRCUL ATIONAHA.117.033369.

12. Alonso A, Barnes AE, Guest JL, Shah A, Shao IY, Marconi V. HIV Infection and Incidence of Cardiovascular Diseases: An Analysis of a Large Healthcare Database. J Am Heart Assoc. 2019;8:e012241. DOI: 10.1161/JAHA.119.012241.

13. Hyle EP, Mayosi BM, Middelkoop K, Mosepele M, Bekker LG, Triant VA, et al. The association between HIV and atherosclerotic cardiovascular 
disease in sub-Saharan Africa: a systematic review. BMC Public Health 2017;17:954 DOI

10.1186/s12889-017-4940-1.

14. Kintu A, Sando D, Guwatudde D, et al. Quantifying the burden of cardiovascular diseases among people living with HIV in sub-Saharan Africa: findings from a modeling study for Uganda. Journal of Global Health Reports. 2020;4:e2020076. doi:10.29392/001c.14377.

15. Panel of Experts from the Metabolic Disorders and Comorbidities Study Group (GEAM) Aids Study Group (GeSIDA), National Aids Plan (PNS).

Executive summary of the consensus document on metabolic disorders and cardiovascular risk in patients with HIV infection. Enferm Infecc Microbiol Clin. 2019;37(1):50-55. https://doi.org/10.1016/j.eim c.2017.06.007.

16. Feinstein MJ, Hsue PY, Benjamin LA, Bloomfield GS, Longenecker CT, Post WS, et al. On behalf of the American Heart Association Prevention Science Committee of the Council on Epidemiology and Prevention and Council on Cardiovascular and Stroke Nursing; Council on Clinical Cardiology; and Stroke Council. Characteristics, Prevention, and Management of Cardiovascular Disease in People Living With HIV: A Scientific Statement from the American Heart Association. Circulation. 2019;140:e98-e124. DOI: 10.1161/CIR.0000000000000695.

17. Bergersen BM, Sandvik L, Bruun JN, Tonstad S. Elevated Framingham score in HIV-positive patients on HAART: results from a Norwegian study of 721 subjects. Eur J Clin Microbiol Infect Dis.2004:23:635-630.

18. Friis-Moller N, Weber R, Riess P, Thiebaut R, Kirk O, d'Arminio MA, et al. Cardiovascular disease risk factors in HIV patients-association with antiretroviral therapy. Results from the D.A.D study. AIDS 2003, 17(8): 1179-1193.

19. Friis-Moller N, Reiss P, Sabin C.A and D.A.D Study Group. Class of antiretroviral drugs and risk of myocardial infarction. N Engl J Med; 2007; 356; 1723-1735.

20. Muhammad S, Sani MU, Okeahialam BN. Cardiovascular disease risk factors among HIV-infected Nigerians receiving highly active antiretroviral therapy. Niger Med J 2013;54:185-90.

21. Ngala RA, Fianko K. Effects of HIV infection and Anti-retroviral Therapy on Cardiovascular Risk Factors. Trends in Molecular Sciences 2014;6(1):112. DOI: 10.3923/tms.2014.1.12.

22. Nsagha DS, Assob JC, Njunda AL, Tanue EA, Kibu OD, Ngowe MN, et al. Risk Factors of Cardiovascular Diseases in HIV/AIDS Patients on HAART. The Open AIDS Journal, 2015, 9, 51-59.

23. Mashinya F, Alberts M, Van geertruyden JP, Colebunders R. Assessment of cardiovascular risk factors in people with HIV infection treated with ART in rural South Africa: a cross sectional study. AIDS Res Ther (2015) 12:42 DOI 10.1186/s12981015-0083-6.

24. D'Agostino RB, Grundy S, Sullivan LM, Wilson P; CHD Risk Prediction Group. Validation of the Framingham coronary heart disease prediction scores: results of a multiple ethnic groups investigation. JAMA. 2001; 286:180-187.

25. Nery MW, Martelli CM, Silveira EA, Sousa CA, Souza LC, Turchi MD, et al. Cardiovascular Risk Assessment: A Comparison of the Framingham, PROCAM, and DAD Equations in HIV-Infected Persons. The Scientific World Journal Volume 2013, Article ID 969281, 9 pages http://dx.doi.org/10.1155/2013/969281.

26. Neto LF, Dias FR, Bressanb FF, Santos CR. Comparison of the ACC/AHA and Framingham algorithms to assess cardiovascular risk in HIVinfected patients. Braz J Infect Dis. 2017;21(6):577-580. http://dx.doi.org/10.1016/j.bjid.2017.06.007.

27. Triant VA, Perez J, Regan S, Massaro JM, Grinspoon SK, D'Agostino RB, et al. Cardiovascular Risk Prediction Functions Underestimate Risk in 
HIV Infection. Circulation. 2018;137:2203-2214. DOI: $10.1161 /$ CIRCULATIONAHA.117.028975.

28. Olusanya O, Okpere E, Ezimokhai M. The importance of Social class in Voluntary Fertility Control in a developing Country. West Afr J Med.1985; 4:4:205212.

29. WHO guidelines on physical activity and sedentary behaviour. Geneva: World Health Organization; 2020. https:/www.who.int/publications/i/item/97892400151 28.

30. WHO Technical report series 854. Physical status. The use and interpretation of anthropometry. WHO, Geneva 1991.

31. Mosteller RD. Simplified Calculation of Body Surface Area. N Eng J Med 1987. Oct 22aq; 317(17):1098 (Letter).

32. Friedewald WT, Levy RI, Fredreckson DS. Estimation of the concentration of low-density lipoprotein cholesterol in plasma without use of the preparative ultracentrifuge. Clin Chem. 1972; 18: 499-502.

33. National kidney foundation GFR calculator. https://www.kidney.org/professionals/kdoqi/gfr_cal culator.

34. Framingham risk score calculator 2008. https://qxmd.com/calculate/calculator_252/frami ngham-risk-score-2008.

35. D'Agostino RB, Vasan RS, Pencina MJ, Wolf PA, Cobain M, Kannel WB, et al. General cardiovascular risk profile for use in primary care: the Framingham Heart Study. Circulation 2008 February 12, 117 (6): 743-53.

36. Chobanian AV, Bakris GL, Black HR, et al. The Seventh Report of the Joint National Committee on Prevention, Detection, Evaluation and Treatment of High Blood Pressure: the JNC-7 report. JAMA 2003; 289: 2560-2570.

37. Saeedi P, Petersohn I, Salpea P, Malanda B, Karuranga S, Williams R, et al. On behalf of the IDF Diabetes Atlas Committee. Global and regional diabetes prevalence estimates for 2019 and projections for 2030 and 2045: Results from the
International Diabetes Federation Diabetes Atlas, 9th edition. Diabetes research and clinical practice. 2019, 157: (2019) 107843.

38. National Cholesterol Education Program: ATP III guidelines at-a-glance quick desk reference. Bethesda, MD: National Institutes of Health; 2001. Available: www.nhlbi.nih.gov/guidelines/chol esterol/atglance.pdf (accessed 2021 January 10).

39. Alberti KG, Zimmet P, Shaw J. The metabolic syndrome - a new worldwide definition. Lancet 2005; 366:1059-1062.

40. Wilson PW, D'Agostino RB, Levy D, Belanger AM, Silbershatz H, Kannel WB. Prediction of coronary heart disease using risk factor categories Circulation. 1998; 97:1837-1847.

41. Kaplan RC, Kingsley LA, Sharrett AR, Lazar J, Tien PC, Mack WJ et al. Ten-year predicted heart disease risk in HIV-infected men and women. Clin Infect Dis.2007; 45:1074-1081.

42. Crum-Ciafone, Teridor R, Medina S, Barahona I, Ganesan A. Obesity among HIV patients: The latest epidemic. AIDS Patient Care STDS.2008:22(12):925-930.

43. Amorosa V, Synnestvedt M, Gross R, Friedman H, MacGregor RR, Gudonis D, et al. A tale of 2 epidemics. The intersection between obesity and HIV infection in Philadelphia. J Acquir Immune Defic Syndr. 2005; 39:557-561.

44. Niaura R, Shadel W.G, Morrow K. Human immunodeficiency virus infection, AIDS and smoking cessation, the time is now. Clin Infect Dis 2000; 31(3):808-812.

45. Touloumi G, Kalpourtzi N, Papastamopoulos V, Paparizos V, Adamis G, Antoniadou A, et al. Cardiovascular risk factors in HIV infected individuals: Comparison with general adult control population in Greece. PLoS ONE 2020;15(3):e0230730.https://doi.org/10.13 71/journal.pone.023 0730.

46. Ferrer E, Minguez C, Marino A, Ceijo P, Brun F, Sanz J et al. Cardiovascular risk estimation in 
Spanish HIV-infected patients: a multicenter cohort study. Journal of International AIDS society 2008:11:92.

47. Roozen GV, Vos AG, Tempelman HA, Venter WD, Grobbee DE, Klipstein-Grobusch K, et al. Cardiovascular disease risk and its determinants in people living with HIV across different settings in South Africa. HIV Medicine 2020;21:386-396. doi:10.1111/hiv.12831.

48. Ekrikpo UE, Akpan EE, Ekott JU, Bello AK, Okpechi IG,Kengne AP. Prevalence and correlates of traditional risk factors for cardiovascular disease in a Nigerian ART-naive HIV population: a cross-sectional study. BMJ Open 2018;8:e019664. doi:10.1136/ bmjopen-2017-019664.

49. Thompson-Paul AM, Lichtenstein KA, Armon C, Palella CJ, Brooks JT, Buchacz K. Cardiovascular Disease Risk Prediction in the HIV Outpatient Study. Clin Infect Dis. 2016; 63(11): 1508-1516. doi:10.1093/cid/ciw615.

50. Dimala CA, Atashili J, Mbuagbaw JC, Wilfred A, Monekosso GL. Prevalence of Hypertension in HIV/AIDS Patients on Highly Active Antiretroviral Therapy (HAART) Compared with HAART-Naïve Patients at the Limbe Regional Hospital, Cameroon. PLoS ONE 2016;11(2): e0148100. doi:10.1371/journal.pone.0148100.

51. Sekai C. Rückera M, Tayeaa A, Bitilinyu-Bangohb J, Ricka F, Maman D, at al. High rates of hypertension, diabetes, elevated low-density lipoprotein cholesterol, and cardiovascular disease risk factors in HIVinfected patients in Malawi. AIDS 2018, 32:253-260.

52. Osegbe ID, Soriyan OO, Ogbenna AA, Okpara HC, Azinge EC. Risk factors and assessment for cardiovascular disease among HIV-positive patients attending a Nigerian tertiary hospital. Pan African Medical Journal. 2016; 23:206 doi:10.11604/pamj. 2016. 23. 206.704.

53. Colditz JA. A meta-analysis of physical activity in the prevention of coronary heart disease. Am J Epidemiol $1990 ; 132: 612-628$.
54. Ding Y, Lin H, Liu X, Zhang Y, Wong FY, He N. Hypertension in HIV-infecte d adults compared with similar but uninfected adults in China: body mass index-dependent effects of nadir CD4 count. AIDS Research and Human Retroviruses 2017.11171125.h ttp://doi.org/10.1089/aid.2017.0008.

55. Manner IW, Trøseid M, Oektedalen O, Baekken M, Os I. Low Nadir CD4 Cell Count Predicts Sustained Hypertension in HIV-Infected Individuals. The Journal of Clinical Hypertension 2013; 15(2): 101106.

56. Mesquita EC, Coelho LE, Amancio RT, Veloso V, Grinsztejn B, Luz P, et al. Severe infection increases cardiovascular risk among HIV-infected individuals. BMC Infectious Diseases 2019;19:319 https://doi.org/10.1186/s12879-019-3894-6.

57. Bergersen BM, Sandvik L, Dunlop O, Birkland K, Bruum JN. Prevalence of Hypertension in HIVpositive patient on HAART compared with HAARTnaïve and HIV negative controls. Results from a Norwegian study of 721 patients. Eur J Clin Microbiol Infect Dis; 2003; 22(12); 731-736.

58. Baekken M, Ingrid O, Sandvik L, Oektedalen O. Hypertension in an urban HIV-positive population compared with the general population; influence of combination antiretroviral therapy. Journal of Hypertension; 2008; 26(11); 2126-2133. 